\title{
A UNIVERSITY LEARNING EXPERIENCE FOR ADULT EDUCATORS IN HIGHER EDUCATION: FROM A RESEARCH-BASED APPROACH TO A GUIDANCE MODEL FOCUSED ON PROFESSIONAL IDENTITY
}

\author{
Andrea Galimberti, Maria Benedetta Gambacorti Passerini, Cristina Palmieri \\ University of Milano Bicocca (ITALY)
}

\begin{abstract}
In Italy, the university training of education professionals currently consists of a three-year bachelor's degree program for educators and a five-year master's degree program for adult educators.

Educational work does not simply consist of direct relationships with the people intended to benefit from it: the provision of educational services demands a significant level of coordination, planning, and organization. In Italy, these functions are performed by adult educators, that is to say, professionals with a Master's Degree who are specialists in educational processes. The specific role of these professionals is to design, manage and evaluate educational services: they may be employed as coordinators, directors, counsellors, or supervisors in the field of education.
\end{abstract}

Italian adult educators must therefore receive training in a range of skills and competences, given that they may be required to fulfil a variety of different roles.

This paper presents and analyses the practical training component in the university training of Italian adult educators, consisting of both e-learning and group sessions. The design of this component was underpinned by a number of generic assumptions, the most important of which is that educators must develop research skills if they are to fully attain the required professional competence.

Specifically, undertaking and conducting research requires the ability to analyze contexts, identify relevant themes, construct and deconstruct issues, and deal with multiple dimensions of knowledge (both theoretical and practical). Designing and implementing a research project in an educational context can make a key contribution to mastering the main skills required by an educational counsellor, supervisor or coordinator. Asking students to carry out research implies viewing them as capable of identifying their own learning interests and developing a clear vision of their professional futures, in other words, as students with agency who are prepared to abandon a purely passive stance.

After this model had been pilot tested for one year, we conducted an evaluation based on feedback received from the participants. The students reported experiencing an unanticipated level of disorientation, which had not been easy for them to cope with. More specifically, they mentioned difficulties in connecting the different perspectives encountered in the course of their studies, recognizing their own competences and negotiating their role with external institutions. Overall, they were disoriented in relation to their own learning interests and future professional identity. These dimensions could not be taken for granted and demanded a space in which to be discussed. The feedback from the evaluation thus led us to look more closely at how the university goes about organizing and managing professional training programs. The role of higher education is changing and the traditional distinctions between formal, non-formal and informal learning called into question. Personal knowledge and transversal skills, as well as the ability to manage a composite and changing professional identity, connect experience acquired across different contexts (formal and non-formal), and identify and construct competences are becoming increasingly relevant. This means that the notion of competence should not be viewed from a purely instrumental perspective but needs to be discussed at multiple levels.

Fostering this kind of reflective process means caring for the "third mission" assigned to universities: that of developing and promoting lifelong and lifewide learning.

Keywords: Adult educators, Master's Degree Course in Educational Science, university training experience; internship, research-based approach; student disorientation. 


\section{TRAINING ADULT EDUCATORS: THE IMPORTANCE OF REFLECTING ON PRACTICE}

The work carried out by adult educators is complex in many respects, and this complexity must be taken into account when planning their education and training. In fact, the organization and operation of educational services requires the ability to design, coordinate, and supervise educational intervention. In Italy, such competences are offered by adult educators, who hold a Master's Degree in educational processes, and whose professional role is to design, manage and evaluate educational contexts.

Coordinating and planning are therefore key skills demanded of adult educators. Other dimensions of their professional competence include the ability to train other educators, and offer counselling or supervision to educational staff [1].

Master's degree programs for adult educators have recently been modified in the context of a reform of the university system. There are currently two Master's courses available that have been specifically designed to train adult educators: LM-50 and LM-85.

Both courses set out to provide adult educators with a strong theoretical foundation in the educational disciplines: this background enables them to understand and design educational intervention. Adult educators must be able to interconnect their knowledge and practical action, via a "circular" movement from theory to practice and vice versa [2]. This movement may also be defined as "reflection on action» [3, p. 57]: the ability to draw on theory to gain a better understanding of practice, and on elements of experience to refine theory. Such an approach also follows Dewey's theory of the heuristic potential of reflective thinking: cognitive and creative ways of thinking about practical or everyday activities, such as professional action [4]. Reflective thinking emancipates us from merely impulsive or routine behavior: it allows us to direct our action, to act intentionally.

Other studies about the development of professional skills conducted during the 1990s also focused on the capability to reflect on action. For example, Jack Mezirow, an American sociologist, emphasized reflection as crucial to professionals' ability to continuously revisit their practice and the knowledge underpinning it. In particular, Mezirow [5] suggested that all professionals should be trained to develop a way of thinking that can orient their practice by understanding, critiquing and, ultimately, redirecting it.

From this perspective, there is a need to design training programs for adult educators that focus on how to read, understand and provide counselling for educational situations, while linking knowledge and practice via reflection.

Practical training for adult educators should thus be designed to help them link theoretical and practical dimensions [6], and to acquire educational wisdom, which is the willingness to continuously question the meaning of educational practice [7].

This means that while training to become adult educators, students should attempt to question educational practice in light of theoretical knowledge, under the supervision of a tutor. Inviting students to adopt the perspective of a researcher can contribute to fostering the reflection required to critically analyze educational practice and services. Clearly, it is not necessary to turn the students into professional researchers; however, research experience can help them to develop their capacity for reflection and critical thinking [8] in relation to exploring and signifying aspects of human life and contexts [9].

Given this background, the current paper offers a reflection on a proposed practical component within the university training of adult educators, which is primarily based on gaining research experience within the educational services, where research is understood as a key opportunity to train students in reflection and critical thinking.

\section{RESEARCH-BASED PRACTICAL TRAINING OR ADULT EDUCATORS: THE INTERNSHIP AS "FIELD OF EXPERIMENTATION"}

Since it was first launched, the Master's Degree Program in Educational Science offered by the University of Milano Bicocca has included a practical training component or internship. This is essential for students to master the tasks, skills and competences of the adult educator they are meant to become, and test the knowledge and abilities acquired from the academic components of the course. 
The main theoretical assumption underpinning the practical training component, as earlier stated, is the idea that research - and in particular qualitative empirical research - is an activity through which students may develop a heuristic and critical attitude and learn to engage in transformative thinking about educational work. In turn, this should foster the development of critical knowledge about the ways, both explicit and implicit, in which educational practices are thought, organized, implemented and evaluated in educational contexts [3] [10].

Therefore, the main concern of the Master's Degree Program is to provide activities enabling students to experience the active, critical and reflective stance required to develop the basic competences of an adult educator who wishes to become a coordinator, supervisor, trainer, or counsellor.

Thus, the internship is thought of as a "field of experimentation" for students, but also for the Master's Degree Program itself. Indeed, in order to develop the practical training provided by this internship to its fullest potential, the Degree Program Boards have constantly striven to identify the most appropriate contents for the training component and the organization required to support it, in light of institutional and economic constraints.

\subsection{The phases in the implementation of the internship}

Since the academic year 2008/2009, the practical training component of the Master's Degree Program has gone through three phases: in each phase, the internship has been organized differently from a didactic point of view, with successive changes informed by continuous evaluation of the practical training outcomes.

In the first phase, the practical training component was entitled "Research and Internship" (2008/2009 - 2012-2013): students were required to conduct a research project that was linked to their thesis. This involved identifying a professor to supervise both the research itself and the related thesis.

In the second phase, the practical training was entitled "Pilot Tutoring for Research and Internship" $(2013 / 2014-2014 / 2015)$. The new model was informed by the evaluation of the prior "Research and Internship Phase", which over time had become inadequate. Indeed, the continuous increase in the number of students enrolled on the program had made it more and more difficult to complete the research activities and theses by the established deadlines. Thus, the Master's Degree Program Board decided to assign resources for starting up and pilot testing a tutoring service. The principal change was the separation of the internship from the writing of the theses.

In the third, and current, phase, the practical component is entitled "Training and Guidance Internship".

In the following section, we focus on the practical training model offered by the second phase entitled "Pilot Tutoring for Research and Internship" and its evaluation outcomes. This brings us to reflect on the critical challenges faced by a Master's Degree Course for Adult Educators, and to identify the conditions under which an internship for such a Course may be effective.

\subsection{Pilot Tutoring for Research and Internship: assumptions and didactic structure}

The Pilot Tutoring component was underpinned by cultural and scientific assumptions that translated into a specific didactic model. These assumptions concerned three different dimensions: the theoretical background to the Pilot Tutoring; the implicit representation of the students; the structure of the Pilot Tutoring component.

The first set of assumptions, under the heading of theoretical background, concerned the basic and transversal competences thought to characterize an adult educator who may become a supervisor, trainer, evaluator, coordinator, or counsellor in the field of education, and who therefore has acquired a "second level" perspective on educational work. These competences were identified as including critical, decisional, communicative, and relational abilities. To develop them, students were viewed as needing firsthand experience of designing and implementing qualitative and empirical research. Such research was viewed as a complex dispositive through which to form heuristic, critical and transformative attitudes [11] [3] [12] [13] [10] [14] [15].

More specifically, in planning and conducting their research projects, students were intended to experiment with strategies and tools of discovery and reflection enabling them to:

- learn about the functioning of educational contexts: this involves identifying the organizational dimensions, cultural framework and epistemological assumptions determining ways of acting in 
a specific educational service. Research based on analysis of the documentation is required to achieve this aim;

- acquire in-depth knowledge of the roles, tasks, competences, potentials and constraints of the "second level" adult educator;

- engage in in-depth reflection on key aspects of educational work via theoretical research.

This set of assumptions, which determined the type of training activity required, implied a further set, concerning the representations and expectations that the coordinator, tutors and program board of the Master's Degree Course with responsibility for designing and evaluating the Pilot Tutoring component, held about the students. Their expectation was that students would be able to:

- identify a research question and the strategies required to answer it;

- choose and implement appropriate methodologies;

- use what they had learned from all the academic learning components of the Master's Degree Course to direct their research and analyze their findings.

The implicit representation, which became more and more evident as the research projects and internships progressed, was that students would be:

- accessible: present on campus;

- appropriately active: self-motivated and self-driven; not just passively following instructions and absorbing contents;

- responsible for their own course of studies: able to identify their own personal aims, and justify them;

- professionally oriented: aware of their professional and personal motivations, and interested in their future work.

In the course of the training and research activities, it became clear that these representations were "ideals": the tutors had to understand this and modify their expectations.

Stemming from the first two sets of assumptions, a third set concerned the structure of the Pilot Course.

First, it was decided to offer the students a "mixed" learning format, which alternated small group sessions held on-campus with individual research activities, within a blended-learning structure [16] [17] [18]. This structure was thought to suit the students on the Master Degree Course, most of whom were already working.

The figure of the tutor and the tutoring service were introduced as the new experimental means of leading students through the practical training component. Tutoring was viewed as a "function with high reflexivity" [19] [20]. Given that the main aim of the training activities was to promote learning through research experience, it seemed appropriate that students should be led by tutors with specific competence in promoting experience-based learning by stimulating reflection on action [3] [7]. Moreover, these tutors were viewed as "pedagogical supervisors", in order to distinguish them from other figures, such as those who assist lecturers and professors in their teaching activities, and help students to prepare for exams or write their theses. The notion of tutor adopted in this Pilot Component included all the functions of tutorship: above all, constructing material and symbolic tutorial settings and monitoring learning processes. Thus, tutors were required to possess the relational and communication skills needed to create an atmosphere of trust and thereby facilitate authentic learning [21]. By this, we mean that while tutor and students continue to occupy clearly differentiated roles, they can experience a closeness that allows students to become aware of how they are experiencing each situation and reflect with their tutor and fellow students on their emotions and thoughts [22] [23].

In addition, the tutors were intended to be professional figures bridging the academic and working worlds. Therefore, they were required to have direct knowledge of the professional world of adult educators - tasks, competences, contexts, etc. - as well as of the academic context and in particular the structure and curriculum of the Master's Degree Program. This twofold knowledge was an essential pre-condition for the tutor to facilitate students in linking their research activity with the knowledge acquired on their academic courses [22] [24]. Specifically, the tutor was required to create suitable conditions for students to use their academic knowledge to develop a research question and 
path of enquiry of their own. This would allow them to make sense of the overall training process as a means of building their professional competences. At the same time, taking a pedagogical supervision approach would allow the tutor to attend to both the contexts and the contents of the students' research, the overall learning experience of each student, and the relational dynamics that evolved within the tutoring settings.

The third and final aspect was the decision to create learning groups. The small group was viewed as a fruitful learning environment that could mediate between students, tutors and the research experience [25] [26] [27]. Moreover, the tutoring group was understood as a "task-centered" training group, in which peers (students) could help one another, thanks to the presence of a tutor with responsibility for the institutional dimension, relational dynamics, and the group's line of thought, in order to facilitate individual students in carrying out their own research. Thus, students were provided with a setting in which to explore differences in their educational backgrounds, professional interests, and work (if they were workers), while also sharing their current training experience [28]. This could also create the conditions for developing new interests and research perspectives, raising questions and working out strategies to answer them, and allowing each student to shape their own research project. Therefore, the tutoring group was intended both to develop personal initiative and independent thinking, and to be in itself an experience, potentially difficult at times, similar to that of a team of professionals that mutually share their thoughts, strategies, doubts, questions, and needs [26]

[29, pp. 107-127].

\subsection{Implementation and outcomes of the Pilot Tutoring}

The Pilot Tutoring began in April 2014. From April to July 2014, 85 students divided into six groups took part in the pilot scheme. Three tutors were appointed: each led two groups. One of the tutors was also coordinator, with responsibility for on-line interaction and activities.

The groups worked at different paces. Therefore, most of them extended their training period beyond the initial deadlines.

The tutors and the members of academic staff with responsibility for reviewing the practical training component (Review Board) also met periodically to evaluate the ongoing training and its outcomes. The Master's Degree Program Board also had an input into the monitoring process. Evaluation was mainly based on the documentation produced during the research activities, as part of the students' individual research projects, and the on-line interaction.

Thus, it was possible to monitor the outcomes of the training process while it was being carried out. The most evident outcome was disorientation. The tutors had the impression that from their first meeting with the students, the latter seemed disorientated regarding both their course of studies and educational path, and their professional prospects, ambitions, and future. This impression caused disorientation in the tutors also. Therefore, they felt obliged to revise their representations of the students and their ideas about the optimum structure for the training.

\section{THE PILOT TUTORING: FEEDBACK ON THE STUDENTS' LIVED EXPERIENCE}

Thus, implementation of the tutoring service gave rise to a series of critical situations that were partly predictable and partly unexpected for students and tutors, who both reported outcomes that did not match their expectations. From the tutors' point of view, these "misunderstandings" provided an opportunity to refine the assumptions underpinning the project. An opportunity to adopt a research and reflexive attitude, the very attitude that was expected of the students. Critical dialogue about assumptions and presuppositions is at the core of transformative learning [5]. Learning processes are successful if they foster reflexivity on the frames of reference that shape our points of view, however this outcome cannot be taken for granted. The conditions for fostering informed dialogue to which each participant may contribute freely and fully must be put in place [5]. Seen from this perspective, the dialogue between tutors and students during the internship period, offered the potential to bring to light ideas about ways of dealing with the academic world that generally act silently.

The Review Board together with the tutors, thanks to online interaction on the web forums and documentation of individual/group supervision, were able to put together a critical overview of the pilot training based on student feedback. 
Two students who were taking part in the training offered to carry out their research projects on the training process itself, with the aim of exploring students' and tutors' expectations and experiences. This research became a means of giving voice to the students and inviting them to adopt a reflexive stance on the learning space they were experiencing.

We now report some of the reflections ${ }^{1}$ that emerged from this dialogical process.

\subsection{What kind of learning approaches did the students expect?}

Students were initially surprised by the active approach they were asked to adopt: they were directly involved in constructing their learning space. This was very different to their previous educational experience:

Students on bachelor's and master's degree programs have been used to dealing with clear ideas, pre-defined tasks to carry out and limited opportunities for creating autonomous learning paths (A.\& A.)

This difference was so marked that a number of students defined the training experience as:

One of the hardest challenges I have ever had to face in my academic career (C.)

What, more specifically, had the students expected to obtain from the training experience?

A well-defined learning path and a mentor willing to engage in a "one to one" relationship based on periodic individual meetings (M.)

Compulsory and predictable stages (S.)

The need for an individual relationship with the tutor, emphasized by the students, shows how difficult it was for them to enter a space that was less defined than a conventional lecture. Structuring a more or less defined learning space is an interplay of possibilities and constraints. On the one hand, a defined structure limits individual creativity and initiative, on the other, the absence of a predictable sequence of tasks may create confusion and uncertainty.

\subsection{What reactions did the students display when asked to construct their own learning interest?}

One of the more critical dimensions emerging from the dialogue between students and tutors was difficulty in forming a learning interest. Defining a personal research question was a challenging task: students experienced great difficulty in identifying a possible field of interest in which to conduct their research. This task, in fact, involves the ability to synthesize and transform knowledge into curiosity, questions and paths of exploration. Furthermore, it requires students to make a connection between their current interests and a future professional identity (What field of intervention attracts me? Where may I begin to approach the broad world of education?):

I have many interests but I'm confused. So I have decided not to panic, I will wait for the spark that will light up my path (R.)

Last winter I was involved in counselling parents at the nursery school where I work and I thought that my research might explore this experience. But now l'm stuck. I have a lot of questions going around my head. Will I keep up the contact with my current work or should I explore new fields? (A.)

\subsection{Did students' different research experiences triggered mutual learning?}

One of the leading assumptions underpinning the design of the pilot training was the idea that difference is a value; the students in contrast perceived this idea to be strange. They found it difficult to compare highly diverse questions and areas of research and were challenged by encountering continuity and discontinuity between their own work and that of others. The very idea of mutual learning was perceived as unusual (a striking finding if we consider that these students were future learning professionals!): some students even refused to share their work because they did not see any possible "benefit" to be got from that.

The fact that we carry out research on so many different topics and at different times is not helpful (L.)

1 These extracts are drawn from students' interactions on on-line forums and from the research conducted by the students Falcinella and Giacomelli. 
Other students, however, found the group interaction meaningful:

The possibility to see other students' work was stimulating, the group encouraged you ( $F$.).

\subsection{How did students experience the virtual dimension of the training?}

The virtual training component, based on an online forum, was intended to give students the opportunity to manage their "attendance" in an independent and flexible way. In particular, this choice was designed to meet the needs of working students who represent a high proportion of those enrolled on the master's degree program. In practice however, the majority of students reported difficulty in experiencing the virtual dimension as meaningful and useful.

One critical dimension regarded the timeframe imposed by the virtual dimension [30]:

It's not like have a discussion with other people...I mean you write your post and you have to wait for days for an answer (M.)

I think that the university is aiming for a certain kind of student: an innovative technician (M.).

Furthermore, the distance perceived in the virtual environment was strongly in contrast with the students' expectations of direct and personal involvement [31]:

The virtual space extinguished, in my opinion, the desire to collaborate. I don't feel part of a group (C.).

I'm not ready to manage this solitude. I never had to learn through an online platform before (C.).

\subsection{Self-orientation: a key dimension of the learning process?}

The training obliged the students to orient themselves both within the "blended" educational setting and in the world outside the academy, in order to carry out meaningful research. The students' voices made continuous reference to this dimension.

l'm lost (M.).

Where do I have to go? (L.).

I could take any direction but too much freedom has made me feel blocked! (A.).

Students highlighted the need to continuously retrace and invent new directions for their learning path:

It was all about self-orientation. Starting out from the initial idea, you have to find the right direction over and over again, the right path to push you forward $(F$.$) .$

Research involves questioning and modifications along the route. It's not possible to conceive of it without obstacles and shortcuts $(F$.$) .$

\section{A PROPOSED NEW FORMAT FOR THE PRACTICAL TRAINING OF ADULT EDUCATORS: A GUIDANCE MODEL}

The new practical training component, based on the feedback from the second phase presented above, attempts to combine two educational pathways: the construction of students' professional profile and practical skills, and research experience, proposed as an opportunity to experience a fruitful exchange between theory and practice, generating reflection.

Students will be divided into groups, with a tutor for each group. The training will be divided into various phases, to be carried out on campus, in external educational contexts or via a virtual blendedlearning platform.

In the first phase of welcome/orientation: students will meet their group and their tutor. The overall practical training program and the virtual platform will be presented.

The second phase is an introduction to research module: students will be trained in designing a research project aimed at exploring and understanding an educational service by bringing to bear the perspective of an adult educator. To this end, the instruments required to explore an educational service, such as interview, observation, reading and analyzing documents, will be presented and explained. This phase will run in parallel with a guidance module designed to accompany students towards the world of work, and focused on gathering information about the profile, role and 
characteristics of adult educators.

These activities will prepare each student for an internship in an educational service, where they will conduct documentary research with a view to exploring and building up an understanding of it as an adult educator.

Later in the process, further steps will be taken to help students develop a professional identity. With this goal in mind, adult educators will be invited to hold seminars for the students, focused on discussing the skills and competences required for educational work. In this specific phase, students will be assisted in conducting a competence mapping process for themselves; each student will have the opportunity to identify an individual portfolio of the professional skills acquired during training.

We thus aim to train adult educators capable of reflecting on themselves, and on their own practice and skills: by reflecting, they stand to continuously gain knowledge from their action and experience. The role of reflection throughout the entire training period will be reinforced by the preparation of a final written report summarizing the entire learning process experienced.

This modified training model is designed to train reflective adult educators capable of critically questioning contexts and practice in relation to theoretical knowledge.

Given this recent shift from a research to a professional guidance emphasis, the new practical training component of the Master's Degree program will require continuous monitoring and evaluation, in order to refine and optimize it without losing sight of its key objectives.

\section{REFERENCES}

[1] Regoliosi, L. \& Scaratti, G. (2002). Il consulente del lavoro socio-educativo. Formazione, supervisione, coordinamento. Carocci. Roma.

[2] Riva, M.G. (2011). II rapporto tra teoria e prassi: una riflessione clinico-pedagogica. Rassegna di Pedagogia 18(1-2), pp. 161-178.

[3] Schön, D. A. (1983). The Reflective Practitioner. London: Temple Smith. Italian edition (2006): Formare il professionista riflessivo. Per una nuova prospettiva della formazione e dell'apprendimento nelle professioni. Franco Angeli. Milano.

[4] Dewey, J. (1910). How we think. D.C. Health \& Company. New York.

[5] Mezirow, J. (1991). Transformative Dimensions of Adult Learning. Jossey-Bass. San Francisco.

[6] Lee, M. \& Fortune, A.E. (2013). Patterns of field learning activities and their relation to learning outcome. Journal of Social Work Education 49(3), pp. 420-438.

[7] Mortari, L. (2003). Apprendere dall'esperienza. Il pensare riflessivo nella formazione. Carocci. Roma.

[8] Murphy, M., Halton, C. \& Dempsey, M. (2008). The transfer of reflective engagement from social work education into the workplace: a study of the value of scaffolded reflection. Irish Educational Studies 27(1), pp. 71-80.

[9] Dahlberg, K., Dahlberg, H. \& Nyström, M. (2008). Reflective Lifeworld Research. Student Litteratur. Hungary.

[10] Fook, J. \& Gardner, F. (2007). Practising Critical Reflection. A Resource Handbook. McGrawHill Education. Maidenhead.

[11] Massa, R. (1992) (Eds.). La clinica della formazione. Un'esperienza di ricerca. FrancoAngeli. Milano.

[12] Mantovani, S. (1998) (Eds.). La ricerca sul campo in educazione. I metodi qualitativi. Bruno Mondadori. Milano.

[13] Mortari, L. (2007). Cultura della ricerca e pedagogia. Prospettive epistemologiche. Carocci. Roma.

[14] Bove, C. (2009). Ricerca educativa e formazione. Contaminazioni metodologiche. FrancoAngeli. Milano. 
[15] Baldacci, M. \& Frabboni, F. (2013). Manuale di metodologia della ricerca educativa. Utet. Torino.

[16] Driscoll, M. (2002). Blended learning: Let's get beyond the hype. E-Learning. Retrieved from http://www-07.ibm.com/services/pdf/blended learning.pdf.

[17] Osguthorpe, R. T. \& Graham, C. R. (2003). Blended learning environments: Definitions and directions. The Quarterly Review of Distance Education, 4(3), pp. 227-233.

[18] Graham, C.R. (2010). Blended Learnings Systems: Definition, current trends, and Future Directions. Handbook of blended learning: Global Perspectives, local designs. Pfeiffer Publishing. San Francisco, CA.

[19] Scandella, O. (2004). Pensare alla tutorship. Riflessioni su una funzione emergente. Adultità 20, pp.110-122.

[20] Zannini, L. (2005). La tutorship nella formazione degli adulti. Uno sguardo pedagogico. Guerini Scientifica. Milano.

[21] Trout, M. G. (2012). Moral Work in Teacher Preparation: Care Pedagogy in a Student Teaching Supervisor's Urban Practice. Dissertation Abstracts International, A: The Humanities and Social Sciences 72(10), pp. 37-17.

[22] Palmieri, C. (2009). La supervisione pedagogica. In Palmieri, C., Pozzoli, B., Rossetti ,S.A. \& Tognetti, S. (Eds.). Pensare e fare tirocinio. Manuale di tirocinio per l'educatore professionale. FrancoAngeli. Milano, pp. 107-127.

[23] Oggionni, F. (2013). La supervisione pedagogica. FrancoAngeli. Milano.

[24] Saltzburg, S. (2010). Using live supervision in field education: Preparing social work students for clinical practice. Families in Society 91(3), pp. 293-299.

[25] Contini, M. (2000). II gruppo educativo. Luogo di scontri e di apprendimenti. Carocci. Roma.

[26] Prada, G. (2009). II tirocinio: un'esperienza individuale in una cornice di gruppo. In Palmieri, C., Pozzoli, B., Rossetti. S.A. \& Tognetti, S. (Eds.). Pensare e fare tirocinio. Manuale di tirocinio per l'educatore professionale. FrancoAngeli. Milano, pp. 232-244.

[27] Meirieu, P. (1984). Itineraires de pédagogie de group. Apprendre on group?. Cronique Social, Lyon.

[28] King, A. (1993). From Sage on the Stage to Guide on the Side. College Teaching 41(1), pp. 3035.

[29] Palmieri, C., Pozzoli, B., Rossetti. S.A. \& Tognetti, S. (2009) (Eds.). Pensare e fare tirocinio. Manuale di tirocinio per l'educatore professionale. FrancoAngeli. Milano.

[30] Islam, N., Beer, M., Slack, F. (2015), E-learning challenges faced by academics in higher education: a literature review. Journal of Education and Training Studies vol. 3, n. 5, pp. 102112.

[31] Haselberg, D. \& Motsching, R. (2016). Students' perspectives on eLearning activities in personcentered, blended learning settings. International Journal on E-learning 15(1), pp. 47-69. 